\title{
Effect of man-made disturbances on understory plant richness of oak forests in Iran
}

\author{
Javad Eshaghi Rad*, Gelare Valadi, Mohammad Reza Zargaran \\ Department of Forestry, Faculty of Natural Resources, Urmia University, P.O. Box 165, Sero Blvd, \\ West Azarbayjan, Iran
}

\begin{abstract}
Eshaghi RAD, J., VALADI, G., Zargaran, M.R., 2017. Effect of man-made disturbances on understory plant richness of oak forests in Iran. Folia Oecologica, 44: 61-68.

The purpose of this study was to investigate the impacts of disturbance degree on the species richness and species diversity of oak forests in the Kurdistan Province (Iran). The study ran on three treatments: undisturbed, moderately disturbed, and highly disturbed. For each treatment, there were selected three forest patches with similar physiographic conditions and on each patch there were specified three $400 \mathrm{~m}^{2}$ plots for recording floristic data. The species' name and the abundance of herbaceous species were recorded on 5 micro plots sized $1.5 \times 1.5 \mathrm{~m}$ for each sample. Menhinick, Margalef, the number of species indices and also rarefaction, jackknife methods and species abundance distribution models were used to estimate the herbaceous species richness for the three treatments. The results showed that all the richness indices had the highest values for the undisturbed forests and the lowest values for the highly disturbed ones. Based on all models, undisturbed forests were showed more diverse than highly disturbed area. Generally the negative impact of human activities (wood cutting and grazing) on the herbaceous species richness was found much stronger in the highly disturbed forests and in moderately disturbed forests compared the undisturbed ones. With increasing destruction intensity, the herbaceous species richness in the oak forests decreased dramatically.
\end{abstract}

\section{Keywords}

disturbance, diversity, oak forest, understory vegetation

\section{Introduction}

Recently, the political and scientific sensitivities concerning biodiversity have increased at the global scale, the expiration rates of species have remarkably increased according to human activities. Ecologists and natural resource managers demonstrate a great attention to the relationship between the habitat destruction and species diversity (EHRLICH and WILSON, 1991). Generally, human disturbances have global negative impacts on the species diversity (ABADIE et al., 2011). However SHERSTHA et al. (2013) showed that all the types of plant diversity increased up to the maximum level where forest disturbance is intermediate in Nepal, Central Himalaya. MLIGor (2011) showed that the anthropogenic disturbance had significant effects on the distribution patterns of plant species, diversity, and biomass. EsTHER et al. (2014) investigated the impact of human activities on tree species richness in Kakamega forest, western Kenya. The results of their study showed that logging had a negative influence on species richness. Also, the study conducted by Kimaro and Lulandala (2013) revealed that logging, charcoaling, and shifting cultivation affected biodiversity integrity of the forests,

*Corresponding author:

e-mail: javad.eshaghi@yahoo.com

(C) 2017 Authors. This is an open access article under the CC BY-NC-ND license (http://creativecommons.org/licenses/by-nc-nd/3.0/) 
The authors report that values of species diversity and composition within the undisturbed forest areas were significantly different from the corresponding values in heavily disturbed areas.

The environmental destruction is caused by natural processes and human activities; hence, a number of parameters are needed to express the current diversity variation due to destruction impacts (AJBILOU et al., 2006). The major concepts in ecology, diversity and richness, can be measured in various ways (GoTELLI and CHAO, 2013). Generally, the observed richness values depend on the sample size, the data from different habitats pooled, due to the species turnover (GoTELLI and ColWell, 2001). In this context, some species richness estimation methods such as rarefaction, jackknife, and bootstrap are applied when the sampling efforts are not compatible (EJTEHADI et al., 2012). In addition, the community structure expressed based on the species abundance distribution models shows how communities are affected by environmental degradation (HAYAK and BuZAs, 2010). The models also show the changes over environmental gradients (MATTHEWs and WHITTAKER, 2014). Rarefaction method is tested or applied in many studies (PALMER, 1990; RicotTA et al., 2012; WiLli et al. 2012; LIMA and VIEIRA, 2013; BERHANE et al, 2015).

Zagros forests are the largest forests and the main oak habitat in Iran. These forests are stretching over Zagros Mountains, reaching a length of $1,150 \mathrm{~km}$ and a width of $75 \mathrm{~km}$ (FATTAHI, 1994). Northern Zagros is the specific habitat of Quercus infectoria Oliv. in some parts mixed with Quercus libanii Oliv., and Quercus brantii Lindl. From past to the present, these forests have been inhabited by residents and nomads. This has resulted in numerous injuries leading to deforestation in some parts and degradation in some other sections. In these forests, people follow a classical form of managing the forest and its products for collecting forage for their animals and wood to be used as fuel (GHZANFARI et al., 2004). Unfortunately, due to social problems and lack of proper and comprehensive management, these forests have been greatly destroyed and they have lost their productivity potential which endangers their future (FATTAHI, 1994). Most of the studies applied in Iran and especially in Zagros forests, have applied the common indices such as Margalef and Menhinick indices for estimating species richness in different areas (Mirdavoodi and ZaHedi, 2005; SHEYKHOLESLAMI et al., 2011; EJTEHADI et al., 2012) with different sampling efforts and sample sizes. The relations between disturbance and species richness and diversity depend on the spatial scale, frequency and the intensity of disturbance and type of species (DuMBrell, et al., 2008). Therefore, understanding the relationship between these factors and species richness and diversity is crucial for conservation programs. Hence, this study aimed at comparing the species richness of the undisturbed, moderately disturbed and highly disturbed oak forests. In this paper we hypothesized that the disturbance degree has different effects on the species richness and diversity, and undisturbed, moderately disturbed and highly disturbed oak forests would have different species richness.

\section{Materials and methods}

\section{Study area}

The research area was located in the Kurdistan province (Iran), latitude from $35^{\circ} 45^{\prime}$ to $36^{\circ} 15^{\prime} \mathrm{N}$ and longitude from $45^{\circ} 30^{\prime} \mathrm{E}$ to $46^{\circ} 15^{\prime} \mathrm{E}$. There were selected nine patches of oak forests (Quercus brantii Lindl) situated on north-facing sites - with similar slope and altitude conditions. The altitude is $1,550 \mathrm{~m}$ and the percentage of slope is between 15 and 23 degree. The mean annual temperature is $13.8^{\circ} \mathrm{C}$, the mean annual rainfall is $657.59 \mathrm{~mm}$ (Pourbabaei and Navgaran, 2011).

\section{Sampling methods}

The field investigation ran during June till August 2016. Oak stands in Zagros forests are loaded with a complex of disturbance regimes including livestock grazing, traditional pole and fuel wood cutting. The livestock grazing and traditional pole and fuel wood cutting may have distinct effects on the herbaceous plant diversity, this study, however, does not distinguish the disturbance types only their intensity levels. The frequency and spatial extent of disturbances in the studied region show that many areas would be affected by these disturbances simultaneously but with different intensity. This could result in different canopy openness. In this study, we categorize the intensity of the above-mentioned disturbances by specifying the canopy openness classes and defining the livestock grazing and traditional wood cutting levels. Therefore, by cruising in oak forest of the region, three disturbance treatments were selected with similar physiographic conditions. The first one was a low disturbed area with more than $50 \%$ canopy cover and trivial destruction effects due to livestock grazing and other forms of traditional pole and fuel wood cutting. The second one was moderately disturbed area with 10 to $50 \%$ canopy coverage and intermediate level of livestock grazing and traditional wood cutting. The last one was a severely disturbed area with less than $10 \%$ canopy of trees and permanent livestock grazing and also extensive pole and fuel wood cutting (MisHrA et al., 2004). For each treatment, there were selected three forest patches with similar physiographic conditions. In each patch, three $400 \mathrm{~m}^{2}$ plots were taken at 0 , 100 and 200 meter on transect, for recording the floristic information (nine plots per a treatment). The species name of herbaceous species were recorded and their abundance was counted on 5 subplots with dimensions $1.5 \times 1.5 \mathrm{~m}$ (Fu et al., 2004; EshaGHIRAD et al., 2011) (Fig. 1). In total, there were 45 plots for each treatment. 
In this study, the size and number of plots were the same in the different treatments.

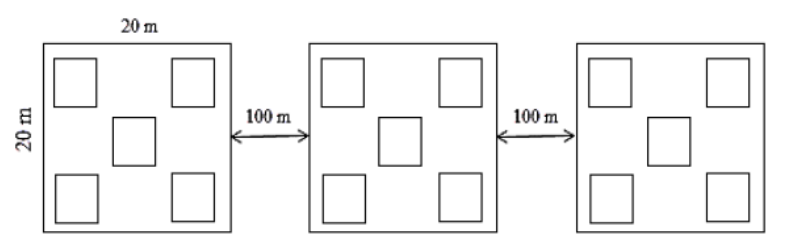

Fig. 1. Schematic image of inventory approach in each patch.

\section{Data analysis}

The Margalef richness index $(\mathrm{Mg})$ and Menhinick index $(\mathrm{Mn})$ were calculated for each plot as common indices which were mainly used in the previous researches in Iran. In addition, rarefaction and jackknife methods were used for assessing or estimating the species richness of herbaceous species in different treatments.

Two kinds of data used in richness studies are distinguished in the present study: (1) incidence data, in which each species in a sample from an assemblage is simply noted as being present, and (2) abundance data, in which the abundance of each species is tallied in each sample (GoTELLI and CHAO, 2013). Incident data were used to estimate species richness by using jackknife and abundance data to estimate species richness by using rarefaction.

Also, four species abundance models including geometric, logarithmic, lognormal, and broken stick were applied. There are three main steps for fitting the models: 1 - drawing the rank-abundance curve, 2 - estimating the distribution parameters and 3 -implementation of the Goodness of Fit test for the distribution model. The SDR Software, version 4.1.2 was used to estimate the species richness and species abundance models. The data normality was tested by KolmogrovSmironov test in which all data distribution were normal. Tukey post hoc test following one way ANOVA was used to compare the plant species richness indices among treatments by using SPSS Software, version 18 .

\section{Results}

The results showed that there were 179 herbaceous species observed in the study area. The total numbers of species in undisturbed, moderately disturbed, and highly disturbed were 117, 109, and 67 respectively.

The results of Menhinick, Margalef and number of species indices show that the highest value was obtained for the undisturbed area and the lowest one for the highly disturbed area. The ANOVA test results for Margalef $(\mathrm{df}=2, \mathrm{~F}=60.752, \mathrm{P}<0.00)$, Menhinick (df $=2, \mathrm{~F}=37.006, \mathrm{P}<0.00)$ and number of species indices $(\mathrm{df}=2, \mathrm{~F}=59.984, \mathrm{P}<0.00)$ showed that there are significant differences amongst different treatments. The Tukey test results revealed that the Margalef and Menhinick indices and number of species index of three treatments had a significant difference when compared to each other (Table 1).

Table 1. The common numerical species richness indices in three different treatments

\begin{tabular}{cccccccccc}
\hline \multirow{2}{*}{$\begin{array}{c}\text { No. of } \\
\text { Quadrat }\end{array}$} & \multicolumn{3}{c}{ Undisturbed } & \multicolumn{3}{c}{ Moderately disturbed } & \multicolumn{3}{c}{ Highly disturbed } \\
\cline { 2 - 10 } & $\begin{array}{c}\text { Mar- } \\
\text { galef }\end{array}$ & $\begin{array}{c}\text { Men- } \\
\text { hinick }\end{array}$ & $\begin{array}{c}\text { No. of } \\
\text { species }\end{array}$ & $\begin{array}{c}\text { Mar- } \\
\text { galef }\end{array}$ & $\begin{array}{c}\text { Men- } \\
\text { hinick }\end{array}$ & $\begin{array}{c}\text { No. of } \\
\text { species }\end{array}$ & $\begin{array}{c}\text { Mar- } \\
\text { galef }\end{array}$ & $\begin{array}{c}\text { Men- } \\
\text { hinick }\end{array}$ & $\begin{array}{c}\text { No. of } \\
\text { species }\end{array}$ \\
\hline 1 & 1.37 & 5.35 & 36 & 1.27 & 4.37 & 28 & 0.92 & 0.08 & 20 \\
2 & 1.51 & 6.90 & 49 & 1.40 & 5.17 & 34 & 0.59 & 0.06 & 14 \\
3 & 1.27 & 5.55 & 39 & 1.19 & 4.60 & 31 & 0.61 & 1.97 & 13 \\
4 & 1.78 & 6.81 & 45 & 1.13 & 4.42 & 30 & 0.75 & 2.89 & 20 \\
5 & 1.80 & 6.95 & 46 & 1.22 & 5.59 & 40 & 0.69 & 2.61 & 18 \\
6 & 1.79 & 6.39 & 41 & 1.47 & 6.11 & 39 & 1.08 & 3.71 & 24 \\
7 & 1.61 & 5.96 & 39 & 1.34 & 5.11 & 34 & 0.75 & 2.45 & 16 \\
8 & 1.97 & 6.92 & 44 & 1.10 & 4.28 & 29 & 0.89 & 3.05 & 20 \\
9 & 1.51 & 5.41 & 35 & 0.937 & 3.54 & 24 & 0.83 & 2.98 & 20 \\
\hline
\end{tabular}

*Different letters show the significant differences. 
The results of rarefaction method are shown in Table 2. On rarefaction curve, the horizontal axis is the number of individuals (abundance) and the vertical axis shows the number of expected species. In this study, 4,761 individuals belonging to 117 herbaceous species in the undisturbed area, 4,671 individuals belonging to 109 herbaceous species in the moderately disturbed area, and 4,986 individuals belonging to 67 herbaceous

Table 2. The rarefaction estimation of species richness for three treatments

\begin{tabular}{ccc}
\hline Treatment & Rarefaction & Standard deviation (SD) \\
\hline Undisturbed & 117 & 0.2088 \\
Moderately disturbed & 109 & 0.0253 \\
Highly disturbed & 66.59 & 0.6213 \\
\hline
\end{tabular}

species in the highly disturbed area were recorded. Undisturbed forest has the highest number of species (117 expected species) and the highly disturbed has the lowest number of species (67) (Fig. 2).

The curve of moderately disturbed area is similar to the curve of the undisturbed forest. Rarefaction curve shows standardized comparison of species richness for three individual-based rarefaction curves. The results of jackknife estimation performed by using the presenceabsence data of 9 quadrats in each forest showed 149, 143.7, and 98.11 species richness in undisturbed forest, moderately disturbed forest and highly disturbed forest, respectively. The results showed the highest richness in the undisturbed area and the lowest richness in the highly disturbed (Table 3 ) one.

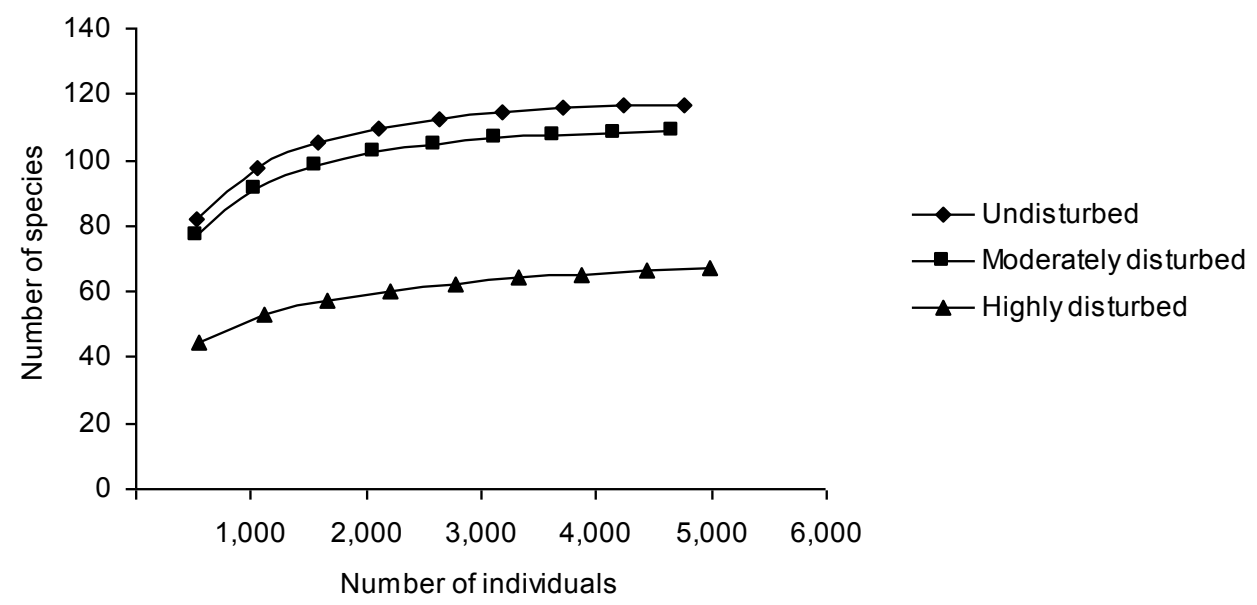

Fig. 2. The rarefaction curve of three treatments.

Table 3. The jackknife estimation of species richness with different number of quadrats for three treatments

\begin{tabular}{cclcccc}
\hline \multirow{2}{*}{ Quadrat } & \multicolumn{2}{c}{ Undisturbed } & \multicolumn{2}{c}{ Moderately disturbed } & \multicolumn{2}{c}{ Highly disturbed } \\
\cline { 2 - 7 } & Species richness & *SD & Species richness & SD & Species richness & SD \\
\hline Using 1 samples & 40.89 & 0 & 32.33 & 0.001 & 16.67 & 0.0001 \\
Using 2 samples & 88.17 & 3.5 & 73.28 & 1.944 & 42.39 & 2.833 \\
Using 3 samples & 103.9 & 4.311 & 95.37 & 4.729 & 52.89 & 2.957 \\
Using 4 samples & 118.2 & 4.145 & 111.7 & 7.308 & 57.59 & 2.874 \\
Using 5 samples & 127.6 & 3.951 & 118.6 & 7.263 & 72.69 & 3.269 \\
Using 6 samples & 134.4 & 3.855 & 126.2 & 6.361 & 79.07 & 3.837 \\
Using 7 samples & 143.1 & 4.035 & 133.4 & 6.178 & 85.56 & 4.257 \\
Using 8 samples & 146.8 & 3.599 & 139.3 & 5.27 & 90.74 & 4.519 \\
Using 9 samples & 149 & 3.528 & 143.7 & 4.807 & 98.11 & 5.067 \\
\hline
\end{tabular}

*SD, standard deviation. 
The rank-abundance curves of three treatments show that the highly disturbed curve has a steeper slope compared with the other two treatments. The rankabundance illustrated the typical shape of the three spe- cies abundance models. The curve demonstrates that the best descriptors of these three assemblages are the lognormal and log relations (Fig. 3).

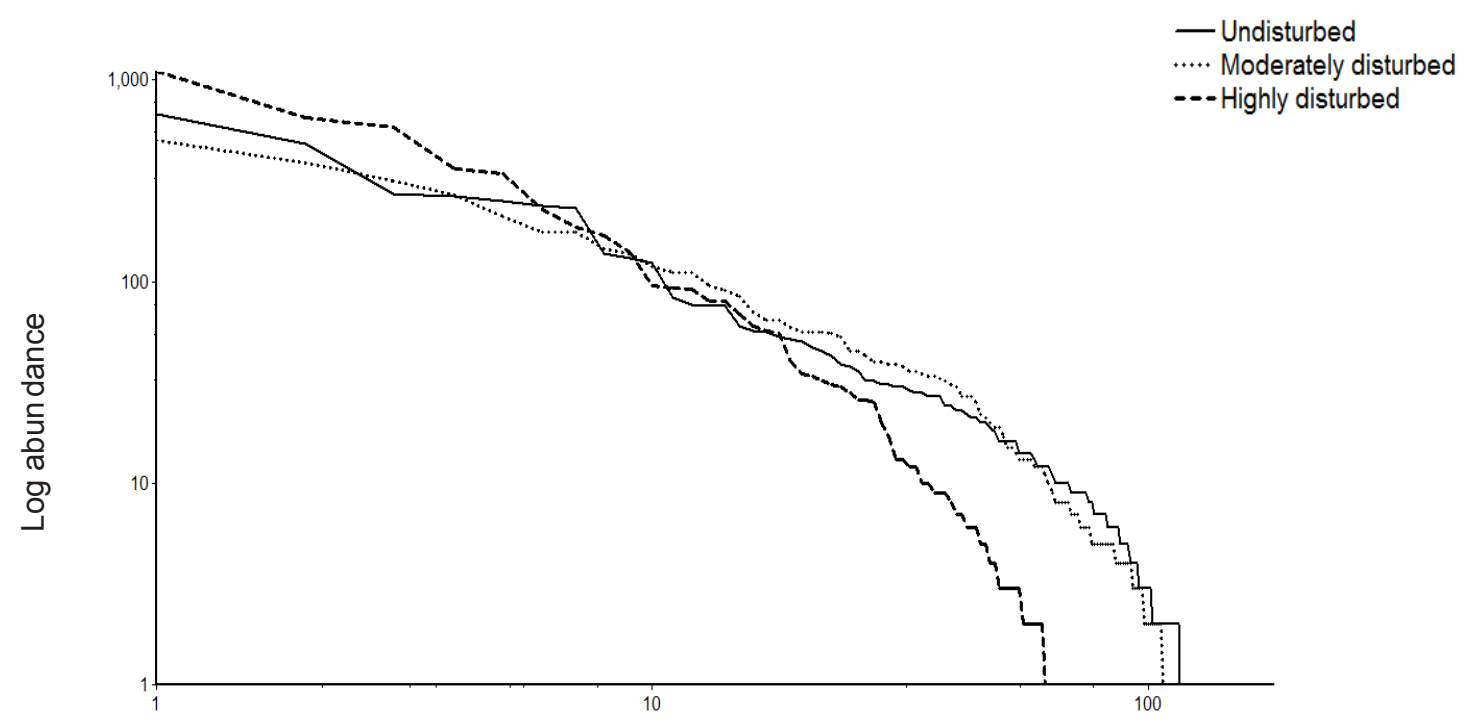

Log species rank

Fig. 3. Rank-abundance curve relating to herbaceous plants in three treatments.

The results of Goodness of fit test in the undisturbed, moderately disturbed and highly disturbed areas are shown in Table 4. The species distribution in the undisturbed and moderately disturbed areas follows the lognormal model and the species distribution in the highly disturbed area follows the lognormal and logarithmic models.

Table 4. The results of Goodness of fit test in undisturbed, moderately disturbed and highly disturbed forests

\begin{tabular}{ccccccccc}
\hline \multicolumn{2}{c}{ Lognormal } & \multicolumn{2}{c}{ Brocken stick } & \multicolumn{2}{c}{ Logarithmic } & \multicolumn{2}{c}{ Geometric } \\
\hline $\mathrm{P}$ & $\mathrm{X}^{2}$ & $\mathrm{P}$ & $\mathrm{X}^{2}$ & $\mathrm{P}$ & $\mathrm{X}^{2}$ & $\mathrm{P}$ & $\mathrm{X}^{2}$ & \\
\hline 0.577 & 5.68 & 0.00 & 57.24 & ${ }^{* * *} 0.00016$ & 30.56 & 0.00 & $1,944.29$ & $\begin{array}{c}\text { Undisturbed } \\
\text { forest }\end{array}$ \\
\hline 0.269 & 9.93 & 0.00 & 55.08 & ${ }^{* * *} 0.00024$ & 27.69 & 0.00 & 729.97 & $\begin{array}{c}\text { Moderately } \\
\text { disturbed } \\
\text { forest }\end{array}$ \\
\hline 0.999 & 0.62 & 0.00 & 101.35 & 0.920925 & 3.20 & 0.00 & $1,789.12$ & $\begin{array}{c}\text { High disturbed } \\
\text { forest }\end{array}$ \\
\hline
\end{tabular}

$*<0.05, * *<0.01, * * *<0.001$.

\section{Discussion}

The results of common richness measures on the herbaceous data showed that Menhinick, Margalef, and the number of species indices had the highest value for the undisturbed forests and the lowest value for the highly disturbed ones (Table 1). The estimation results obtained using the rarefaction and jackknife methods were similar, the highest related to the undisturbed forest and the lowest to the highly disturbed forest. The 
highest cumulative rarefaction curve belonged to the undisturbed area due to maintenance of the species in the habitat and the lowest curve belonged to the highly disturbed area due to the removal of a large number of species from this habitat. These findings are related to large open gaps within highly disturbed patches that create a dry microclimate reducing the herbaceous species richness (ESTHER et al., 2014). Large open gaps within the highly disturbed forests create a dry climate which interferes with the small amount of herbaceous establishment. This reduces herbaceous species richness and diversity in the long run. Also, increased wind flow, because of position of these open spaces in the highly disturbed patches, increases water loss from the soil surface and decreases air humidity, which could be unfavorable for some plant species (HARPER, 2005). Furthermore, illegal cutting of mature trees from the oak forests, which are important in providing suitable microclimate and soil moisture under the canopy for herbaceous plant establishment, resulted in decreasing the species richness. So an increase in canopy cover in the oak forests from highly disturbed (less than 10\%) to undisturbed ones (more than 50\%) would lead to an increase in the species richness (Tables 1,2). Similarly, MAJUMDAR (2015) illustrated that the effects of anthropogenic disturbances in Northeast India resulted in declining the level of all diversity indices. Moreover, ONAINDIA et al. (2004) investigated the biodiversity in various destructive conditions of mixed oak forests in the north of Spain and found out that the species richness of the herbs were higher in the stands with less destruction.

Low slope of rank-abundance curves of the undisturbed and moderately disturbed areas (Fig. 3) showed more species richness compared to the highly disturbed (Fig. 3). This result might be due to the lack of more common and rare species in the undisturbed and moderately disturbed areas (BELL et al., 2000). Also the results showed that the best model fitted for undisturbed and moderately disturbed areas was lognormal (Table 4). The lognormal model indicates communities with high species richness and diversity (OLIVEIRA and BATALHA, 2005; OliveIRA and BatalHa, 2005), so undisturbed and moderately disturbed forests should have more species richness. Besides Mishra et al. (2004), reported the log-normal curve in undisturbed and moderately disturbed stands and stated that this indicated the complex and stable nature of the community. Also highly disturbed forest followed lognormal and logarithmic models. The shift from lognormal to logarithmic reveals the destruction, and the changes in the species abundance distribution can act as an early warning for the effects of disturbance on biodiversity, as the shape of the species distribution model can change markedly before any local extinctions happened (Mouillot et al., 2013). Generally, impacts of disturbance on different plant diversity and richness are complex, and the investigation of relations between them depends on the types of indices considered (SHERSTHA et al., 2013). The results of the present study illustrated that there was negative impact of human activities (wood cutting and grazing) on the herbaceous species richness in the highly disturbed forests and moderately disturbed forests compared to the undisturbed ones in the oak forests studied.

\section{Conclusion}

All numerical and non-numerical richness measures used in this research illustrate that with increasing destruction intensity, the herbaceous species richness in the oak forests decreased dramatically. It can be concluded that the herbaceous species richness in the examined oak forests decreased dramatically according to the man-made disturbances degree Therefore a comprehensive program regarding the forest conservation in this region should be considered to transform the highly disturbed forests to moderately disturbed ones in the short time plan. Furthermore, the study recommended that forest managers should pay more attention to the needs of local communities for natural resources use in the future programs.

\section{Acknowledgement}

We thank Mr. Maroufi for his help in the field work and plants identification.

\section{References}

Abadie, JC., Machon, N., Muratet, A., Porcher, E., 2011. Landscape disturbance causes small-scale functional homogenization, but limited taxonomic homogenization, in plant communities. Journal of Ecology, 99: 1134-1142.

Ajbilou, R., Maranon, T., Arroyyo, J., 2006. Ecological and biogeographical analyses of Mediterranean forests of northern Morocco. Acta Oecologica, 29: 104-113.

Bell, G., Lechowicez, M. J., Waterway, M. J., 2000. Environmental heterogeneity and species diversity of forest sedges. Journal of Ecology, 88: 67-87.

Berhane, A., Totland, Ø., Haile, M., MOE, S.R., 2015. Intense use of woody plants in a semiarid environment of Northern Ethiopia: effects on species composition, richness and diversity. Journal of Arid Environments, 114: 14-21.

Dumbrell, A., Clark, E., Frost, G., Randell, T., Pitchford, J., Hill, J., 2008. Changes in species diversity following habitat disturbance are dependent on spatial scale: theoretical and empirical evidence. Journal of Applied Ecology, 45: 1531-1539.

EHRLICH, P.R., Wilson, E., 1991. Biodiversity studies: science and policy. Science, 253 (5021): 758-762. 
Ejtehadi, H., Sepehri, A., AKafi, H., 2012. Methods of measuring biodiversity. Mashhad: Ferdosi University of Mashhad. 228 p. (in Persian)

Eshaghi Rad, J., Heidari, M., Mahdavi, A., ZinivanDZADEH, M., 2011. Impact of recreational activities on vegetation and soil in forest park. Iranian Journal of Forest, 3 (1): 71-80. (in Persian)

Esther, V., Martha, K., Harrison, T., Lenard, O., Charles, K., Stella, W., Humphrey, N., 2014. The impacts of human activities on tree species richness and diversity in Kakamega forest, Western Kenya. International Journal of Biodiversity and Conservation, 6 (6): 428-435.

FATTAHI, M., 1994. Study on Zagros oak forest and the most important their destruction causes. Sanandaj, Iran: Institute of Forest and Rangelands Research Press. 64 p. (in Persian)

Fu, B.J., LiU, S.L., MA, K.M., Zhu, Y.G., 2004. Relationships between soil characteristics, topography and plant diversity in a heterogeneous deciduous broad-leaved forest near Beijing, China. Plant and Soil, 261 (1): 47-54.

Ghazanfari, H., Namiranian, M., Sobhani, H., MoHAJER, M.R., 2004. Traditional forest management and its application to encourage public participation for sustainable forest management in the northern Zagros mountain of Kurdistan province, Iran. Scandinavian Journal of Forest Research, 19 (Issue sup004): 65-71. (in Persian)

Gotelli, N.J., Colwell, R.K., 2001. Quantifying biodiversity: procedures and pitfalls in the measurement and comparison of species richness. Ecology Letters, 4 (4): 379-391.

Gotelli, N.J., ChaO, A., 2013. Measuring and estimating species richness, species diversity, and biotic similarity from sampling data. Encyclopedia of Biodiversity, 5: 195-211.

Harper, K.A, Macdonald, S., Barton, P., Chen, J., Brosoffske, K., 2005. Edge influence of forest structure and composition in fragmentation landscapes. Conservation Biology, 19: 1-15.

HAYAK, L.A. C., BuZAs, M. A., 2010. Surveying natural populations: quantitative tools for assessing biodiversity. Columbia University Press. 592 p.

Hemantha, S., Herath, B., Kumar, P., 2002. The Jackknife estimator for estimating volatility of volatility of a stock. Corporate Finance Review, 7(3):13-21.

KIm, D.H., Cho, W.S., Chon, T.S., 2013. Self-organizing map and species abundance distribution of stream benthic macroinvertebrates in revealing community patterns in different seasons. Ecological Informatics, 17: 14-29.

Kimaro, J., Lulandala, L., 2013. Human influence on tree diversity and composition of coastal forest ecosystem: the case of Ngumburuni forest reserve, Rufiji, Tanzania. International Journal of Forestry Research, 25:1-7.

LimA, T.A., VIEIRA, G., 2013. High plant species richness in monospecific tree plantations in the Central
Amazon. Forest Ecology and Management, 295: 77-86.

Magurran, A.E., 2004. Measuring biological diversity. Blackwell Science Ltd. Chapter 2. 215 p.

MaJUmDar, K., 2015. Effects of anthropogenic disturbances on vegetation diversity and structure: a case study in the remnant forests surrounding the village ecosystems of Tripura, Northeast India. Chinese Journal of Population Resources and Environment, 4: 332-340.

Matthews, T.J., Whittaker, R.J., 2014. Neutral theory and the species abundance distribution: recent developments and prospects for unifying niche and neutral perspectives. Ecology and Evolution, 4 (11): 2263-2277.

McGILl, B.J. (eds). Biological diversity: frontiers in measurement and assessment. New York: Oxford University Press, p. 39-54.

Mirdavoodi, H.R., Zahedi, H.A., 2005. Determination of suitable species diversity model for Meyghan playa plant association and effect of some ecological factors on diversity change. Journal of $\mathrm{Pa}$ jouhesh and Sazandegi, 68: 56-65. (in Persian)

Mishra, B., Tripathi, O., Tripathi, R., Pandey, H., 2004. Effects of anthropogenic disturbance on plant diversity and community structure of a sacred grove in Meghalaya, northeast India. Biodiversity \& Conservation, 13 (2): 421-436.

Mligo, C., 2011. Anthropogenic disturbance on the vegetation in Makurunge woodland, Bagamoyo district, Tanzania. Tanzania Journal of Science, 37: 94-108.

Mouillot, D., Lepretre, A., 2000. Introduction of relative abundance distribution (RAD) indices, estimated from the rank-frequency diagrams (RFD), to assess changes in community diversity. Environmental Monitoring and Assessment, 63 (2): 279-295.

Mouillot, D., Grahan, N.A., Villeger, S., Mason, N.W., Bellwood, D.R., 2013. A functional approach reveals community responses to disturbances. Trends in Ecology \& Evolution, 28 (3): 167-177.

Oliveira, F.F., BatalHA, M.A., 2005. Lognormal abundance distribution of woody species in a cerrado fragment (São Carlos, southeastern Brazil). Brazilian Journal of Botany, 28 (1): 39-45.

Onaindia, M., Domiguez, I., Albizo, I., Garbisu, C. Amezage, I., 2004. Vegetation diversity and vertical structure as indicators of forest disturbance. Forest Ecology and Management, 195: 341-354.

PAlmer, M.W., 1990. The estimation of species richness by extrapolation. Ecology, 71: 1195-1199.

Pourbabaei, H., Navgran, S., 2011. Study on floristic and plant species diversity in the Lebanon oak (Quercuslibani) site, Chenareh, Marivan, Kordestan Province, western Iran. Biocenose Journal, 3 (1): 15-22. 
Ricotta, C., Pavoline, S., Bacaro, G., Acosta, A.T., 2012. Functional rarefaction for species abundance data. Methods in Ecology and Evolution, 3 (3): 519-525.

Sheikholeslami, A., Kiapasha, Kh., Kialashaki, A., 2011. A study of tree distribution in diameter classes in natural forests of Iran. Annals of Biological Research, 5: 283-290.

Sherstha, K., Maren, I., Arneberg, E., SAh, J., VetaAS, O., 2013. Effect of anthropogenic disturbance on plant species diversity in oak forests in Nepal, Cen- tral Himalaya. International Journal of Biodiversity Science, Ecosystem Services and Management, 1: 21-29.

Willie, J., Petre, Ch., Tag, N., 2012. Evaluation of species richness estimators based on quantitative performance measures and sensitivity to patchiness and sample grain size. Acta Oecologica, 45: 31-41.

Received January 14, 2017 Accepted October 6, 2017 